\title{
Safety and Feasibility of Oral Rehydration Solution Prior to Endoscopic Retrograde Cholangiopancreatography
}

\author{
Takamitsu Sasaki*, Daisuke Kato, Ryohei Sakamoto, Satoshi Shinya, Hironari Shiwaku, \\ Kanefumi Yamashita, Ryo Nakashima, Yuichi Yamashita \\ Department of Gastroenterological Surgery, Fukuoka University School of Medicine, Fukuoka, Japan \\ Email: ${ }^{*}$ takamitu@fc4.so-net.ne.jp
}

Received 2 February 2015; accepted 26 February 2015; published 28 February 2015

Copyright (C) 2015 by authors and Scientific Research Publishing Inc.

This work is licensed under the Creative Commons Attribution International License (CC BY). http://creativecommons.org/licenses/by/4.0/

(c) (i) Open Access

\begin{abstract}
Purpose: The safety of oral rehydration therapy before endoscopic screening with respect to vital signs and complications after the screening procedure was assessed in patients undergoing endoscopic retrograde cholangiopancreatography (ERCP). Methods: A total of 107 patients scheduled for ERCP were assigned to either the intravenous drip injection (DIV) group during fasting (56 patients) or ORS group given oral rehydration solution (51 patients) prior to endoscopy. Vital signs after ERCP, including blood pressure and temperature, blood biochemical data and the incidence of post-ERCP complications were compared between the groups. Results: No cases of aspiration pneumonia were detected in either groups. Moreover, there were no statistically significant differences between the DIV group and ORS group in terms of the biochemical data and vital signs after ERCP. The intergroup difference in the development of pancreatitis after ERCP was 2.3\% [95\% CI: $-5.7,10.3]$, which was not statistically significant. Conclusions: The safety of oral rehydration therapy was found to be equivalent to that of the customary practice of infusion as a method for managing hydration and replenishing electrolytes in patients receiving ERCP. Oral rehydration therapy may be easily utilized as rehydration therapy prior to endoscopic screening for ERCP and other procedures.
\end{abstract}

\section{Keywords}

Endoscopic Retrograde Cholangiopancreatography, Oral Rehydration Therapy, Oral Rehydration Solution, Post-ERCP Pancreatitis, Complication

\footnotetext{
${ }^{*}$ Corresponding author.
}

How to cite this paper: Sasaki, T., Kato, D., Sakamoto, R., Shinya, S., Shiwaku, H., Yamashita, K., Nakashima, R. and Yamashita, Y. (2015) Safety and Feasibility of Oral Rehydration Solution Prior to Endoscopic Retrograde Cholangiopancreatography. Surgical Science, 6, 91-99. http://dx.doi.org/10.4236/ss.2015.63015 


\section{Introduction}

Fasting starting the night before endoscopy remains the customary practice for preventing aspiration pneumonia. Therefore, it is inevitable that the patient will become thirsty and hungry. In addition, it has been demonstrated that this approach has no scientific basis; thus, the need for fasting is being reconsidered.

Endoscopic retrograde cholangiopancreatography (ERCP) is an endoscopic procedure essential for the close diagnosis and treatment of pancreatobiliary diseases. However, this technique is invasive and the incidence of complications is not low. In particular, ERCP-induced pancreatitis is a severe complication, with a reported frequency of $2 \%-15 \%$ [1] [2].

Patients receiving ERCP are also often instructed to fast starting the night before in the same manner as that used for standard endoscopy. Hence, the patient is often dehydrated during screening, which raises concerns regarding the potential development of pancreatitis, a common ERCP complication, as well as the vasovagal reflex.

In recent years, the use of oral rehydration therapy (ORT) has drawn increasing attention and its efficacy in preventing dehydration and as a treatment for mild dehydration has been reevaluated. OS-1 is an oral rehydration solution (ORS), a special purpose food product, used for rehydration and to replenish electrolytes in patients experiencing diarrhea, vomiting or fever. Some studies have reported the efficacy of this treatment in patients exhibiting mild dehydration in daily practice and as a rehydration therapy before and after invasive procedures. However, no previous reports related to the use of this technique in clinical trials of endoscopic screening have been published.

The purpose of our research was to examine the effects of ORT before endoscopy on vital signs and complications in patients undergoing ERCP.

\section{Methods}

\subsection{Patients}

The subjects of this study included patients admitted or making outpatients visits to the department of gastroenterological surgery from January 2012 to December 2013, at Fukuoka University Hospital for ERCP. Among these individuals, those 20 years of age or older who agreed in writing to participate in this study were registered. Patients who did not receive oral rehydration or had a previous history of laparotomy for gastroesophageal surgery and those whose participation was assessed by the physician to be inappropriate were excluded. The present study was conducted in accordance with the principles of the Declaration of Helsinki. Sample collection and all administrative procedures in this study were carried out in accordance with the code of ethics specified by the Institutional Ethics Committee of Fukuoka University Hospital.

\subsection{Oral Rehydration Therapy Prior to Endoscopy}

The patients were allocated to two groups: the ORS group, who received $500 \mathrm{ml}$ of oral rehydration solution (OS-1, Otsuka Pharmaceutical Factory, Tokushima, Japan) up to one hour prior to ERCP, and the DIV group, who remained under complete fasting on the day of ERCP and were treated with an intravenous drip (Table 1). The results obtained from interviews and data, such as vital signs, including blood pressure and temperature, blood biochemical findings and the incidence of post-ERCP complications, were compared (Figure 1).

\subsection{Statistical Analysis}

Continuous data are reported as the mean \pm standard deviation (SD) if normally distributed and the median and interquartile range (IQR) if not normally distributed. Categorical data are presented as numbers (n) and percentages (\%). Student's $t$-test was used for comparisons of the mean values between the two groups. Some of the data were not normally distributed; in these cases, the nonparametric Mann-Whitney U test was used instead of the $t$-test. Categorical variables were evaluated using Fisher's exact test. Previous reports have shown the incidence of ERCP-induced pancreatitis to range from $2 \%$ to $15 \%$. Therefore, we determined that a significant medical risk was present when the difference in the incidence of ERCP-induced pancreatitis between the intravenous drip group and the ORS group was more than $13 \%$. A P value of less than 0.05 was considered to be statistically significant. All statistical analyses were performed with the SPSS v22.0 package for Windows (IBM Japan, Ltd., Tokyo, Japan). 
Table 1. Composition of the oral rehydration solution (OS-1).

\begin{tabular}{lc}
\hline Volume (ml) & 500 \\
Energy (kcal) & 50 \\
Carbohydrate (\%) & 2.5 (glucose, 1.8) \\
Electrolytes $\left(\mathrm{mEq} \cdot \mathrm{l}^{-1}\right.$ ) & 50 \\
$\quad$ Sodium & 20 \\
$\quad$ Potassium & 2 \\
$\quad$ Magnesium & 50 \\
$\quad$ Chloride & 31 \\
$\quad$ Lactate & 2 \\
$\quad$ Phosphorus $\left(\mathrm{mmol} \cdot \mathrm{l}^{-1}\right)$ & 3.9 \\
pH & 270 \\
Osmolarity $\left(\mathrm{mOsm} \cdot \mathrm{l}^{-1}\right)$ &
\end{tabular}

\begin{tabular}{|c|c|c|c|c|c|c|}
\hline & & \multirow[t]{2}{*}{ Day before endoscopy } & \multicolumn{3}{|c|}{ Day of endoscopy } & \multirow[t]{2}{*}{ Day after endoscopy } \\
\hline & & & 1h before ERCP & ERCP & 2h after ERCP & \\
\hline & $\begin{array}{l}\text { ORS group } \\
\text { DIV group }\end{array}$ & $\longleftarrow$ & $\begin{array}{l}- \text { Fasting } \longrightarrow \\
\leftarrow \quad 500 \mathrm{ml} \\
\longleftarrow \quad 500 \mathrm{ml}\end{array}$ & & & \\
\hline $\begin{array}{l}\text { Aspiration } \\
\text { Vital signs } \\
\text { Blood biochemical data } \\
\text { Complication }\end{array}$ & & 0 & $\begin{array}{l}0 \\
0\end{array}$ & 0 & $\begin{array}{l}0 \\
0 \\
0 \\
0\end{array}$ & $\begin{array}{l}0 \\
0 \\
0 \\
0\end{array}$ \\
\hline
\end{tabular}

Figure 1. Schedule of treatment in the current study. ORS group, oral rehydration solution group (OS-1; oral rehydration solution: Otsuka Pharmaceutical Factory, Tokushima, Japan). DIV group, underwent complete fasting on the day of ERCP and given treatment with an intravenous drip.

\section{Results}

\subsection{Baseline Characteristics of the Study Subjects}

A total of 107 patients scheduled for ERCP between January 2012 and December 2013 were assigned to either the DIV group who received treatment with an intravenous drip while fasting (56 patients) or the ORS group who was given oral rehydration solution (51 patients) prior to endoscopy, and the two groups were compared.

As shown in Table 2, the drip group and the ORS group demonstrated no significant differences in terms of gender (drip group: 31 males and 25 females; ORS group: 25 males and 26 females), age (drip group: $68.9 \pm$ 10.2; OS-1 group: $70.5 \pm 10.8$ ) or diagnosis.

\subsection{ERCP-Related Procedures in the DIV and ORS Groups}

No statistically significant differences in ERCP-related procedures, including screening of the papillary region, endoscopic retrograde pancreatography (ERP), balloon-ERP, pancreatic juice cytology, endoscopic retrograde cholangiography (ERC), endoscopic sphincterotomy (EST), lithotripsy using a wire basket, endoscopic biliary stenting (EBS), endoscopic nasobiliary drainage (ENBD), endoscopic papillectomy and endoscopic minor papilla sphincterotomy, were noted between the DIV group and the OS-1 group, as shown in Table 3.

\subsection{Biochemical Data and Vital Signs after ERCP}

As indicated in Table 4, the test data, including systolic blood pressure, diastolic blood pressure, pulse, body temperature, hemoglobin $(\mathrm{Hb})$, hematocrit (Hct), blood urea nitrogen (BUN), serum creatinine (Cr), serum 
Table 2. Baseline characteristics of the study subjects.

\begin{tabular}{|c|c|c|c|c|c|c|c|c|}
\hline \multirow[b]{2}{*}{ Age, years, mean \pm SD } & \multicolumn{3}{|c|}{ DIV group $(n=56)$} & \multicolumn{3}{|c|}{ ORS group $(n=51)$} & \multicolumn{2}{|c|}{ P-value } \\
\hline & 68.9 & \pm & 10.2 & 70.5 & \pm & 10.8 & 0.435 & $\mathrm{a}$ \\
\hline Gender (male/female) & \multicolumn{3}{|c|}{$31 / 25$} & \multicolumn{3}{|c|}{$25 / 26$} & 0.564 & c \\
\hline Diagnosis & & & & & & & 0.592 & c \\
\hline Choledocholithiasis & 26 & & 46.4 & 23 & & 45.1 & & \\
\hline Pancreatic adenocarcinoma & 17 & & 30.4 & 16 & & 31.4 & & \\
\hline Obstractive jaudice & 5 & & 8.9 & 8 & & 15.7 & & \\
\hline Chronic pancreatitis & 1 & & 1.8 & 2 & & 3.9 & & \\
\hline Distal cholangiocarcinoma & 3 & & 5.4 & 2 & & 3.9 & & \\
\hline Pancreas divism & 3 & & 5.4 & 0 & & 0.0 & & \\
\hline Pancreaticobiliary maljunction & 1 & & 1.8 & 0 & & 0.0 & & \\
\hline
\end{tabular}

Note: mean \pm SD, median [IQR]. n, \%. a: Independent t test; b: Mann-Whitney U test; c: Fisher’s exact test.

Table 3. ERCP-related procedures in the DIV and ORS groups.

\begin{tabular}{|c|c|c|c|c|c|}
\hline \multirow[b]{2}{*}{ Screening papillary region } & \multicolumn{2}{|c|}{ DIV group $(n=56)$} & \multicolumn{2}{|c|}{ ORS group $(n=51)$} & \multirow{2}{*}{$\begin{array}{c}\text { P-value } \\
0.707\end{array}$} \\
\hline & 3 & 5.4 & 4 & 7.8 & \\
\hline ERP & 11 & 19.6 & 10 & 19.6 & $>0.999$ \\
\hline Balloon-ERP & 5 & 8.9 & 1 & 2.0 & 0.209 \\
\hline Pancreatic juice cytology & 2 & 3.6 & 2 & 3.9 & $>0.999$ \\
\hline ERC & 3 & 5.4 & 5 & 9.8 & 0.474 \\
\hline EST & 8 & 14.3 & 6 & 11.8 & 0.779 \\
\hline Lithotripsy & 14 & 25.0 & 15 & 29.4 & 0.667 \\
\hline EBS & 7 & 12.5 & 8 & 15.7 & 0.782 \\
\hline ENBD & 0 & 0.0 & 0 & 0.0 & - \\
\hline Papillectomy & 1 & 1.8 & 0 & 0.0 & $>0.999$ \\
\hline Minor papilla sphincterotomy & 2 & 3.6 & 0 & 0.0 & 0.496 \\
\hline
\end{tabular}

Note: n, \%. P-value: Fisher's exact test. ERP, endoscopic retrograde pancreatography; ERC, endoscopic retrograde cholangiograpy; EST, endoscopic sphincterotomy; EBS, endoscopic biliary stenting; ENBD, endoscopic nasobiliary drainage.

sodium (Na), serum potassium (K), serum chloride (Cl), blood glucose (Glu), white blood cells (WBCs), C-reactive protein (CRP) and serum amylase (AMY), obtained after ERCP showed no statistically significant differences between the DIV and ORS groups.

\subsection{Incidence of Post-ERCP Pancreatitis in the DIV and ORS Groups}

As shown in Table 5, the intergroup difference in the incidence of post-ERCP pancreatitis between the DIV group and the ORS group was $2.3 \%$ [95\% CI: $-5.7,10.3$ ], which did not rise to the level of statistical significance. In addition, the absolute value of the $95 \%$ confidence interval for the intergroup difference in the incidence of pancreatitis was less than $13 \%$, defined as a medically significant difference in the Methods section. Therefore, the incidence of pancreatitis was not considered to be medically significant in the DIV or ORS group.

\section{Discussion}

Oral rehydration therapy (ORT) using oral rehydration solution (ORS) was originally developed to treat dehydration in developing nations. WHO-oral rehydration salt (WHO-ORS), developed by the World Health 
Table 4. Biochemical data and vital signs after ERCP.

\begin{tabular}{|c|c|c|c|c|c|c|c|c|c|c|c|}
\hline \multirow[b]{3}{*}{ Systoric blood pressure (mmHg) } & \multirow{2}{*}{\multicolumn{3}{|c|}{ DIV group $(\mathrm{n}=56)$}} & \multirow{2}{*}{\multicolumn{3}{|c|}{ ORS group $(\mathrm{n}=51)$}} & \multicolumn{3}{|c|}{$\Delta[\mathrm{DIV}-\mathrm{ORS}](\%)$} & \multirow{2}{*}{\multicolumn{2}{|c|}{ P-value }} \\
\hline & & & & & & & \multirow{2}{*}{$\begin{array}{c}\text { Mean } \\
1.2\end{array}$} & \multicolumn{2}{|c|}{$95 \%$ CI } & & \\
\hline & 129.6 & \pm & 16.1 & 130.9 & \pm & 20.6 & & -5.8 & 8.3 & 0.732 & a \\
\hline Diastolic blood pressure (mmHg) & 77.2 & \pm & 12.4 & 74.4 & \pm & 12.1 & -2.8 & -7.5 & 1.9 & 0.233 & a \\
\hline Pulse & 68.7 & \pm & 10.7 & 67.3 & \pm & 12.2 & -1.4 & -5.8 & 2.9 & 0.517 & a \\
\hline Body temperature & 36.5 & \pm & 0.6 & 36.6 & \pm & 0.7 & 0.1 & -0.2 & 0.3 & 0.645 & $\mathrm{a}$ \\
\hline Hemoglobin & 12.5 & \pm & 1.6 & 12.1 & \pm & 1.4 & -0.4 & -1.0 & 0.2 & 0.170 & $\mathrm{a}$ \\
\hline Hematocrit & 37.3 & \pm & 4.2 & 36.5 & \pm & 4.1 & -0.8 & -2.4 & 0.8 & 0.320 & $\mathrm{a}$ \\
\hline Blood urea nitrogen & 12.1 & \pm & 5.2 & 11.9 & \pm & 5.1 & -0.2 & -2.1 & 1.8 & 0.880 & $\mathrm{a}$ \\
\hline Serum creatinine & 0.8 & \pm & 0.3 & 0.8 & \pm & 0.2 & -0.1 & -0.1 & 0.0 & 0.253 & $\mathrm{a}$ \\
\hline Serum sodium $\left(\mathrm{mEq} \cdot \mathrm{l}^{-1}\right)$ & 139.7 & \pm & 2.1 & 139.8 & \pm & 3.2 & 0.1 & -1.0 & 1.1 & 0.886 & $\mathrm{a}$ \\
\hline Serum potassium $\left(\mathrm{mEq} \cdot \mathrm{l}^{-1}\right)$ & 4.1 & \pm & 0.4 & 4.0 & \pm & 0.5 & -0.1 & -0.2 & 0.1 & 0.539 & $\mathrm{a}$ \\
\hline Serum chloride $\left(\mathrm{mEq} \cdot \mathrm{l}^{-1}\right)$ & 104.5 & \pm & 2.6 & 103.6 & \pm & 3.8 & -0.8 & -2.1 & 0.4 & 0.182 & $\mathrm{a}$ \\
\hline Blood glucose & 136.9 & \pm & 47.0 & 152.1 & \pm & 53.8 & 15.2 & -4.2 & 34.6 & 0.123 & $\mathrm{a}$ \\
\hline White blood cell & 6271.4 & \pm & 3247.6 & 6811.8 & \pm & 2492.8 & 540.3 & -577.5 & 1658.2 & 0.340 & $\mathrm{a}$ \\
\hline C-reactive protein & 0.1 & & $0,0.8)$ & 0.2 & & $0,1.6)$ & & & & 0.264 & $\mathrm{~b}$ \\
\hline Serum amylase & 100.5 & $(70$ & $3,133.5)$ & 104.0 & & , 148.0) & & & & 0.635 & $\mathrm{~b}$ \\
\hline
\end{tabular}

Note: mean \pm SD, median [IQR]. P-value: a: Independent t test; b: Mann-Whitney U test; 95\% CI: 95\% confidence interval.

Table 5. Incidence of post-ERCP pancreatitis in the DIV and ORS groups.

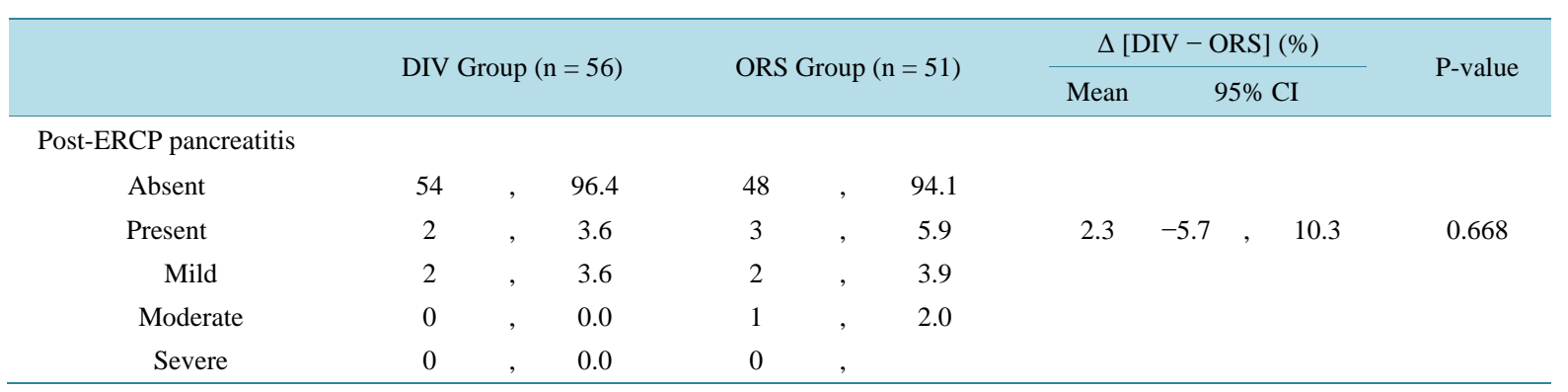

Note: n, \%. P-value: Fisher's exact test. [Post-ERCP pancreatitis (absent or present) vs. group (DIV or OS-1)].

Organization (WHO), demonstrates significant success in dehydrated patients experiencing acute diarrhea due to cholera and the efficacy of this treatment in developing nations is widely recognized [3] [4]. In recent years, the use of ORS has drawn attention in many countries, including Europe and the US, as an option for rehydration therapy to rehydrate the patient and replenish electrolytes and glucose at an equivalent volume to fluid therapy [4]-[6]. The guidelines of the Center for Disease Control and Prevention (CDC) recommend the application of ORS in cases of mild to moderate dehydration [5]. The OS-1 used in this study is a special purpose food product created based on the idea of ORT recommended by the WHO and whose composition is aligned with the policy of the American Academy of Pediatrics [6]. In comparison to regular soft drinks, the efficacy of this treatment in treating dehydration and achieving postoperative rehydration with electrolyte replenishment has been recognized [7].

In the current study, ORT was used to manage the levels of body fluids prior to ERCP and the safety and efficacy of this approach before endoscopy were examined. Consequently, no patients showed the pre-ERCP ORT-triggered accumulation of excess gastric fluid or experienced issues with testing. Furthermore, no complications of aspiration pneumonia were noted, and the post-ERCP vital signs, including blood pressure and temperature, blood biochemical data and the incidence of post-ERCP complications were not significantly different 
between the group given ORT and the group given sufficient transfusion via infusion. Therefore, using ORT for the management of rehydration and electrolyte replenishment in ERCP patients was found to be feasible and safe as a customary method for achieving rehydration via infusion.

For endoscopic screening, patients are normally instructed to fast for a certain period of time, with the goal of reducing the gastric fluid volume (GFV) in order to prevent vomiting and aspiration during the screening procedure. However, long-term fasting inflicts burdens on the patient, such as thirst and hunger, and dehydration has the potential to worsen the patient's condition in association with a low blood sugar level and perioperative complications. Previous studies have shown that food/fluid intake prior to surgery is safe when complying with guidelines regarding suggested contents and timing, which has led to a reevaluation of the need for fasting [8]. Various societies of anesthesiologists in both Europe and the US have revised their guidelines concerning preoperative fasting and proposed that the intake of clear fluids up to two to three hours before the operation is acceptable, with the exception of cases in which delayed gastric emptying is expected [9]-[12]. In addition, in recent years, Fearon et al. suggested the efficacy of ERAS (enhanced recovery after surgery) as a method for reducing the perioperative stress response and comprehensively decreasing the incidence of complications and demonstrated the adverse effects of perioperative fasting [13]. Moreover, various studies of ERAS have confirmed that carbohydrate (CHO) intake prior to surgery reduces insulin resistance in adult patients. Furthermore, it has been reported that thirst and hunger resulting from fasting increase the mental burden and level of anxiety in preoperative patients, whereas CHO intake overcomes these negative aspects [14].

Endoscopic retrograde cholangiopancreatography (ERCP) is a technique developed by McCune et al. in 1968 and Takagi et al. and Ohi in 1969 and subsequently became widely used worldwide [15]. Since then, as an extension of this technique, various treatment methodologies have been developed and evolved. However, adverse outcomes, such as pancreatitis, are not rare, and measures to reduce these complications remain challenging. As to the complications of ERCP, pancreatitis, hemorrhage and gastrointestinal perforation are the primary examples, among which pancreatitis may be severe and/or fatal. Various reports of high-risk groups regarding the development of ERCP-induced pancreatitis have been published. Fisk factors include a young age, female gender, normal pancreatogram findings, previous history of ERCP-induced pancreatitis, recurrent acute pancreatitis and sphincter of Oddi dysfunction (SOD), etc., while operative risk factors involve the level of experience of the physician performing the operation, frequent pancreatography, precut EST, endoscopic papillary balloon dilatation (EPBD) and difficult intubation [1] [16]-[20]. Currently, treatment protocols for the treatment of acute pancreatitis based on evidence-based medicine comprise the use of massive transfusions at the early stage of onset and the administration of prophylactic antibiotics only. Furthermore, evidence regarding the efficacy of protease inhibitor therapy does not support the use of continuous arterial drop therapy. Although identifying high-risk groups and administering treatments such as preventive medications and pancreatic duct stent placement have been attempted as preventive measures for reducing the incidence of ERCP-induced pancreatitis, no effective strategies have been confirmed [21]-[27]. Therefore, providing sufficient hydration to prevent the onset of dehydration around the time of testing due to the effects of fasting is more critical in patients undergoing endoscopic screening than in other cases. However, patients undergoing ERCP are normally instructed to fast starting the night before the procedure, similar to that required for normal endoscopy. Therefore, patients frequently complain of thirst and hunger at the time of testing and are often dehydrated, raising concern about the potential development of pancreatitis, a common ERCP complication, as well as the vasovagal reflex.

\section{Conclusion}

In this study, the safety of ORT was found to be equivalent to that of the customary practice of infusion as a method for managing hydration and replenishing electrolytes in patients receiving ERCP. Moreover, it is possible that the use of ORT may decrease unwanted feelings of thirst and hunger and reduce the psychological burden on the patient. Hence, oral rehydration therapy is thought to be an effective therapy for rehydration prior to ERCP and other endoscopic procedures.

\section{Acknowledgements}

The authors thank Hajime Yamakage (Satista Co. Ltd.) for providing assistance with the statistical analyses. Manuscript editing services were provided by Cactus Communications Pvt. Ltd. 


\section{Author Contributions}

Conception and design: Takamitsu Sasaki, Daisuke Kato, Yuichi Yamashita. Development of methodology: Takamitsu Sasaki, Daisuke Kato, Yuichi Yamashita. Acquisition of data: Takamitsu Sasaki, Daisuke Kato, Ryohei Sakamoto, Hironari Shiwaku, Kanefumi Yamashita, Satoshi Shinya, Ryo Nakajima, Yuichi Yamashita. Analysis and interpretation of data: Takamitsu Sasaki, Daisuke Kato, Yuichi Yamashita. Writing, review, and/or revision of the manuscript: Takamitsu Sasaki, Daisuke Kato, Ryohei Sakamoto, Hironari Shiwaku, Kanefumi Yamashita, Satoshi Shinya, Ryo Nakashima, Yuichi Yamashita. Administrative, technical, or material support: Takamitsu Sasaki, Daisuke Kato, Yuichi Yamashita. Study supervision: Takamitsu Sasaki, Daisuke Kato, Yuichi Yamashita. Final approval for submitting the manuscript: Takamitsu Sasaki, Daisuke Kato, Ryohei Sakamoto, Hironari Shiwaku, Kanefumi Yamashita, Satoshi Shinya, Ryo Nakashima, and Yuichi Yamashita.

\section{Conflicts of Interest}

None of the authors have any potential conflicts of interest with regard to this study.

\section{Financial Disclosures}

The authors report no proprietary or commercial interests in any products mentioned or concepts discussed in this article.

\section{References}

[1] Masci, E., Toti, G., Mariani, A., Curioni, S., Lomazzi, A., Dinelli, M., Minoli, G., Crosta, C., Comin, U., Fertitta, A., Prada, A., Passoni, G.R. and Testoni, P.A. (2001) Complications of Diagnostic and Therapeutic ERCP: A Prospective Multicenter Study. American Journal of Gastroenterology, 96, 417-423. http://dx.doi.org/10.1111/j.1572-0241.2001.03594.x

[2] Wang, P., Li, Z.S., Liu, F., Ren, X., Lu, N.H., Fan, Z.N., Huang, Q., Zhang, X., He, L.P., Sun, W.S., Zhao, Q., Shi, R.H., Tian, Z.B., Li, Y.Q., Li, W. and Zhi, F.C. (2009) Risk Factors for ERCP-Related Complications: A Prospective Multicenter Study. American Journal of Gastroenterology, 104, 31-40. http://dx.doi.org/10.1038/ajg.2008.5

[3] Farthing, M.J. (1994) Oral Rehydration Therapy. Pharmacology Therapeutics, 64, 477-492. http://dx.doi.org/10.1016/0163-7258(94)90020-5

[4] World Health Organization (2002) Oral Rehydration Salts (ORS): A New Reduced Osmolarity Formulation. World Health Organization, Geneva.

[5] Centers for Disease Control and Prevention (2003) Managing Acute Gastroenteritis among Children: Oral Rehydration, Maintenance, and Nutritional Bherapy. MMWR Recomm Rep 52 (No. RR-16), 1-16.

[6] Mauer, A.M., Dweck, H.S., Finberg, L., Holmes, F., Reynolds, J.W., Suskind, R.M., Woodruff, C.W. and Hellerstein, S. (1985) American Academy of Pediatrics Committee on Nutrition: Use of Oral Fluid Therapy and Posttreatment Feeding Following Enteritis in Children in a Developed Country. Pediatrics, 75, 358-361.

[7] Goseki, N., Hiranuma, S., Yamazaki, S., Maruyama, M., Nakajima, K., Gen, T. and Shirataka, M. (2007) Oral Rehydration Solution for Providing Water and Electrolytes Following Laparoscopic Cholecystectomy and Recovery of Intestinal Function. Hepatogastroenterology, 54, 2276-2281.

[8] McIntyre, J.W. (1998) Evolution of 20th Century Attitudes to Prophylaxis of Pulmonary Aspiration during Anaesthesia. Canadian Journal of Anesthesia, 45, 1024-1030. http://dx.doi.org/10.1007/BF03012312

[9] American Society of Anesthesiologists Committee (2011) Practice Guidelines for Preoperative Fasting and the Use of Pharmacologic Agents to Reduce the Risk of Pulmonary Aspiration: Application to Healthy Patients Undergoing Elective Procedures: An Updated Report by the American Society of Anesthesiologists Committee on Standards and Practice Parameters. Anesthesiology, 114, 495-511. http://dx.doi.org/10.1097/ALN.0b013e3181fcbfd9

[10] Smith, I., Kranke, P., Murat, I., Smith, A., O’Sullivan, G., Søreide, E., Spies, C. and In’t Veld, B. (2011) European Society of Anaesthesiology. Perioperative Fasting in Adults and Children: Guidelines from the European Society of Anaesthesiology. European Journal of Anaesthesiology, 28, 556-569. http://dx.doi.org/10.1097/EJA.0b013e3283495ba1

[11] Søreide, E., Eriksson, L.I., Hirlekar, G., Eriksson, H., Henneberg, S.W., Sandin, R. and Raeder, J., Task Force on Scandinavian Pre-Operative Fasting Guidelines, Clinical Practice Committee Scandinavian Society of Anaesthesiology and Intensive Care Medicine (2005) Pre-Operative Fasting Guidelines: An Update. Acta Anaesthesiologica Scandinavica, 49, 1041-1047. 
[12] Merchant, R., Chartrand, D., Dain, S., Dobson, J., Kurrek, M., LeDez, K., Morgan, P. and Shukla, R., Canadian Anesthesiologists' Society (2012) Guidelines to the Practice of Anesthesia Revised Edition 2012. Canadian Journal of Anesthesia, 59, 63-102. http://dx.doi.org/10.1007/s12630-011-9609-0

[13] Fearon, K.C., Ljungqvist, O., Von Meyenfeldt, M., Revhaug, A., Dejong, C.H., Lassen, K., Nygren, J., Hausel, J., Soop, M., Andersen, J. and Kehlet, H. (2005) Enhanced Recovery after Surgery: A Consensus Review of Clinical Care for Patients Undergoing Colonic Resection. Clinical Nutrition, 24, 466-477. http://dx.doi.org/10.1016/j.clnu.2005.02.002

[14] Nygren, J., Thorell, A., Jacobsson, H., Larsson, S., Schnell, P.O., Hylén, L. and Ljungqvist, O. (1995) Preoperative Gastric Emptying Effects of Anxiety and Oral Carbohydrate Administration. Annals of Surgery, 222, 728-734. http://dx.doi.org/10.1097/00000658-199512000-00006

[15] McCune, W.S., Shorb, P.E. and Moscovitz, H. (1968) Endoscopic Cannulation of the Ampulla of Vater: A Preliminary Report. Annals of Surgery, 167, 752-756. http://dx.doi.org/10.1097/00000658-196805000-00013

[16] Freeman, M.L., Nelson, D.B., Sherman, S., Haber, G.B., Herman, M.E., Dorsher, P.J., Moore, J.P., Fennerty, M.B., Ryan, M.E., Shaw, M.J., Lande, J.D. and Pheley, A.M. (1996) Complications of Endoscopic Biliary Sphincterotomy. New England Journal of Medicine, 335, 909-919. http://dx.doi.org/10.1056/NEJM199609263351301

[17] Christensen, M., Matzen, P., Schulze, S. and Rosenberg, J. (2004) Complications of ERCP: A Prospective Study. Gastrointestinal Endoscopy, 60, 721-731. http://dx.doi.org/10.1016/S0016-5107(04)02169-8

[18] Freeman, M.L., DiSario, J.A., Nelson, D.B., Fennerty, M.B., Lee, J.G., Bjorkman, D.J., Overby, C.S., Aas, J., Ryan, M.E., Bochna, G.S., Shaw, M.J., Snady, H.W., Erickson, R.V., Moore, J.P. and Roel, J.P. (2001) Risk Factors for Post-ERCP Pancreatitis: A Prospective, Multicenter Study. Gastrointestinal Endoscopy, 54, 425-434. http://dx.doi.org/10.1067/mge.2001.117550

[19] Loperfido, S., Angelini, G., Benedetti, G., Chilovi, F., Costan, F., De Berardinis, F., De Bernardin, M., Ederle, A., Fina, P. and Fratton, A. (1998) Major Early Complications from Diagnostic and Therapeutic ERCP: A Prospective Multicenter Study. Gastrointestinal Endoscopy, 48, 1-10. http://dx.doi.org/10.1016/S0016-5107(98)70121-X

[20] Masci, E., Mariani, A., Curioni, S. and Testoni, P.A. (2003) Risk Factors for Pancreatitis Following Endoscopic Retrograde Cholangiopancreatography: A Meta-Analysis. Endoscopy, 35, 830-834. http://dx.doi.org/10.1055/s-2003-42614

[21] Cavallini, G., Tittobello, A., Frulloni, L., Masci, E., Mariana, A. and Di Francesco, V., Gabexate in Digestive Endoscopy-Italian Group (1996) Gabexate for the Prevention of Pancreatic Damage Related to Endoscopic Retrograde Cholangiopancreatography. New England Journal of Medicine, 335, 919-923. http://dx.doi.org/10.1056/NEJM199609263351302

[22] Masci, E. and Mariani, A. (2003) Short-Term Prophylactic Prevention of Post-ERCP Pancreatitis. Gastrointestinal Endoscopy, 58, 816. http://dx.doi.org/10.1016/S0016-5107(03)02000-5

[23] Devière, J., Le Moine, O., Van Laethem, J.L., Eisendrath, P., Ghilain, A., Severs, N. and Cohard, M. (2001) Interleukin 10 Reduces the Incidence of Pancreatitis after Therapeutic Endoscopic Retrograde Cholangiopancreatography. Gastroenterology, 120, 498-505. http://dx.doi.org/10.1053/gast.2001.21172

[24] Dumot, J.A., Conwell, D.L., Zuccaro Jr., G., Vargo, J.J., Shay, S.S., Easley, K.A. and Ponsky, J.L. (2001) A Randomized, Double Blind Study of Interleukin 10 for the Prevention of ERCP-Induced Pancreatitis. American Journal of Gastroenterology, 96, 2098-2102. http://dx.doi.org/10.1111/j.1572-0241.2001.04092.x

[25] Murray, B., Carter, R., Imrie, C., Evans, S. and O’Suilleabhain, C. (2003) Diclofenac Reduces the Incidence of Acute Pancreatitis after Endoscopic Retrograde Cholangiopancreatography. Gastroenterology, 124, 1786-1791. http://dx.doi.org/10.1016/S0016-5085(03)00384-6

[26] Singh, P., Das, A., Isenberg, G., Wong, R.C., Sivak Jr., M.V., Agrawal, D. and Chak, A. (2004) Does Prophylactic Pancreatic Stent Placement Reduce the Risk of Post-ERCP Acute Pancreatitis? A Meta-Analysis of Controlled Trials. Gastrointestinal Endoscopy, 60, 544-550. http://dx.doi.org/10.1016/S0016-5107(04)02013-9

[27] Freeman, M.L., Overby, C. and Qi, D. (2004) Pancreatic Stent Insertion: Consequences of Failure and Results of a Modified Technique to Maximize Success. Gastrointestinal Endoscopy, 59, 8-14.

http://dx.doi.org/10.1016/S0016-5107(03)02530-6 


\section{Abbreviations}

ERCP: Endoscopic retrograde cholangiopancreatography;

DIV: Intravenous drip injection;

ORT: Oral rehydration therapy;

ORS: Oral rehydration solution;

ERP: Endoscopic retrograde pancreatography;

ERC: Endoscopic retrograde cholangiography;

EST: Endoscopic sphincterotomy;

EBS: Endoscopic biliary stenting;

ENBD: Endoscopic nasobiliary drainage;

EPBD: Endoscopic papillary balloon dilatation. 
Scientific Research Publishing (SCIRP) is one of the largest Open Access journal publishers. It is currently publishing more than 200 open access, online, peer-reviewed journals covering a wide range of academic disciplines. SCIRP serves the worldwide academic communities and contributes to the progress and application of science with its publication.

Other selected journals from SCIRP are listed as below. Submit your manuscript to us via either submit@scirp.org or Online Submission Portal.
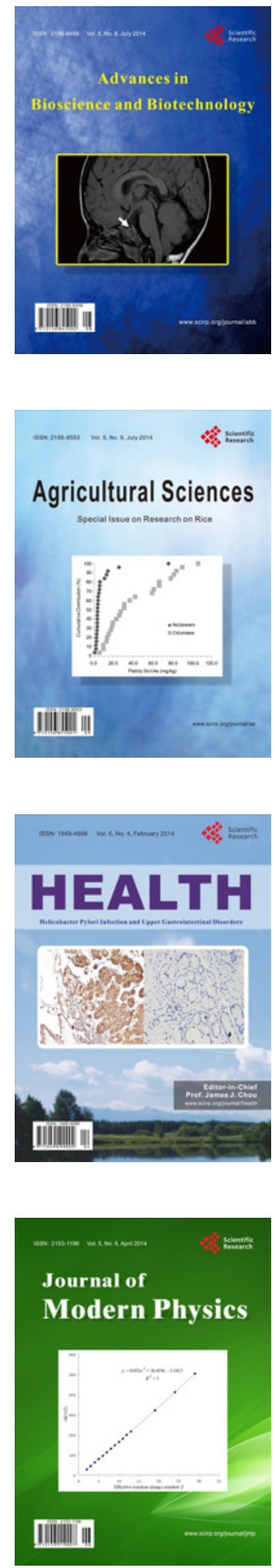
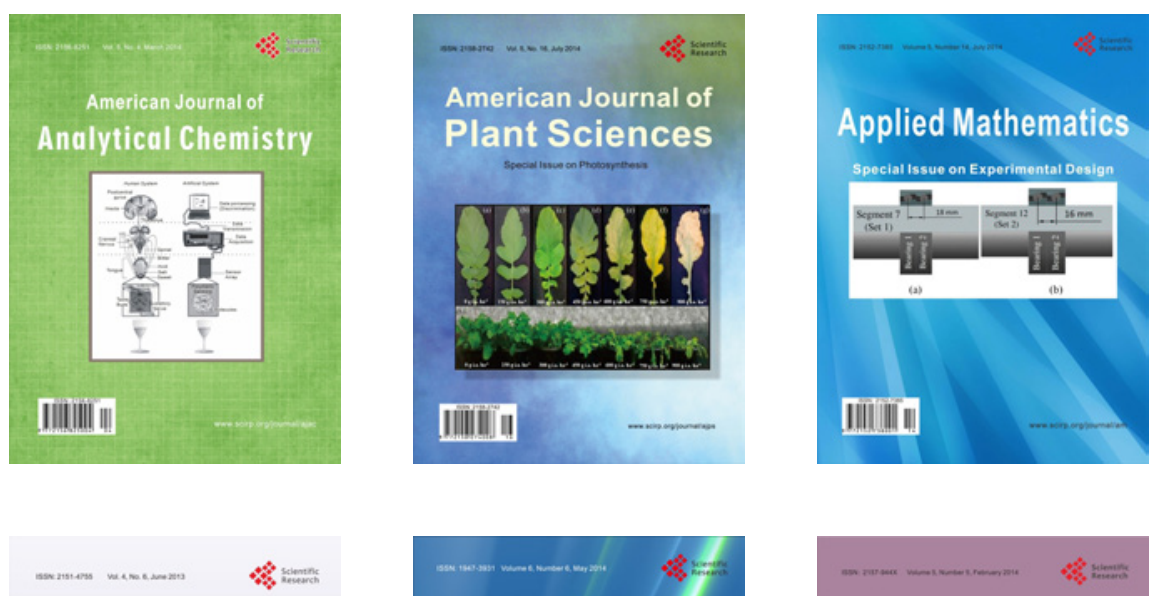

Creative Education
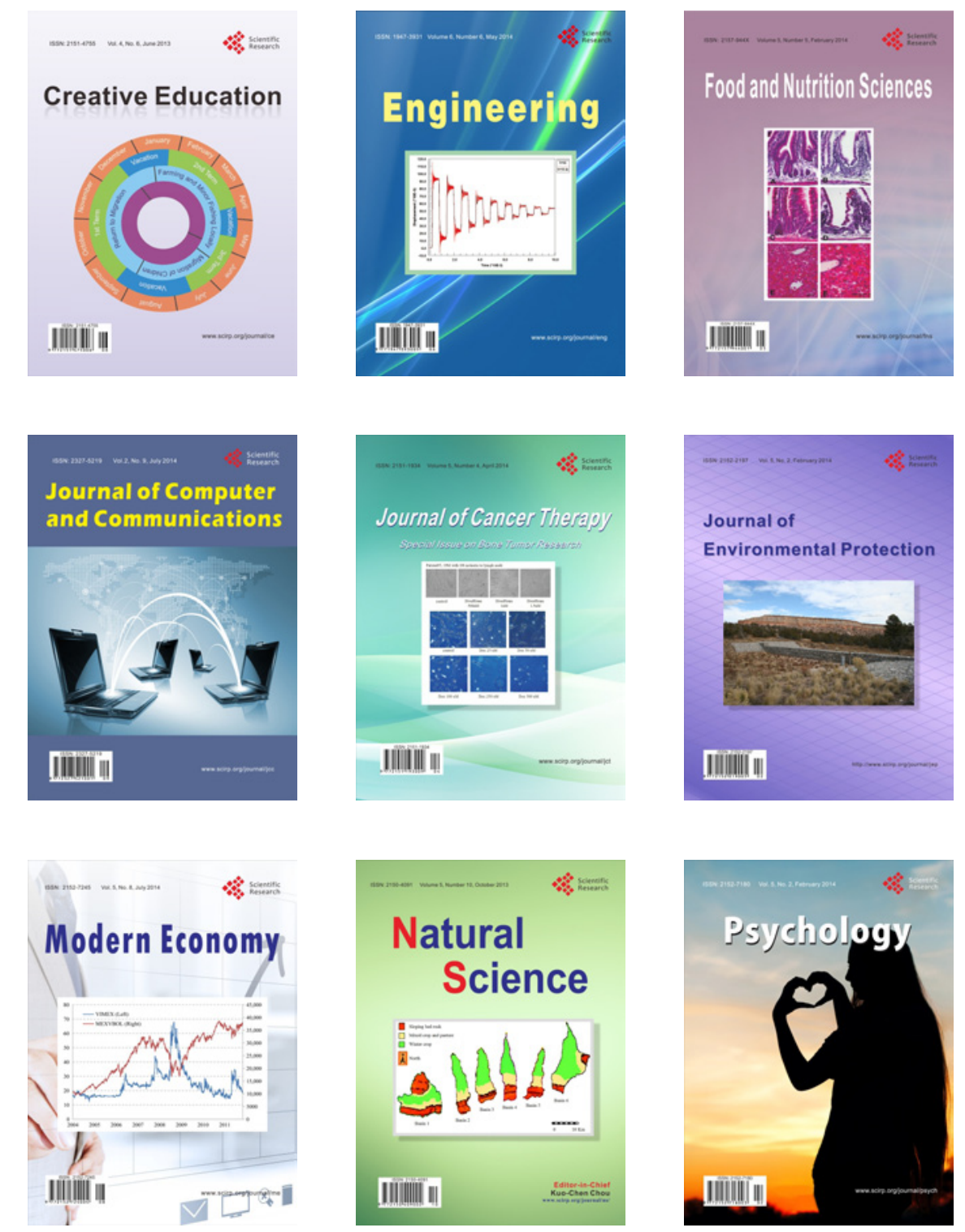